\title{
Non-communicable diseases surveillance: overview of magnitude and determinants in Kenya from STEPwise approach survey of 2015
}

Richard G Wamai ${ }^{1 *}$, Andre Pascal Kengne ${ }^{2}$ and Naomi Levitt ${ }^{3,4}$

\section{Background}

Disease surveillance is a scientifically and legally established hallmark of population health whose goal is systematically collecting, interpreting and disseminating data to target and monitor interventions to reduce disease morbidity and mortality [1-5]. However, data is often either lacking or of low quality especially in lowand- middle-income countries (LMICs). For example, more than half of global deaths for 2015 did not have an established cause [6]. The Global Burden of Disease (GBD), the largest descriptive epidemiological study, show low rates of data quality for most LMICs during 1980-2016 [7]. Despite substantial improvements in data quality and cause of death establishment $[8,9]$, of over 50 health-related Sustainable Development Goals (SDGs) indicators identified in the World Health Statistics 2017 report, data is adequate for monitoring 36 indicators [10].

Lack of, and low, quality data is exacerbated by data inconsistencies between sources often due to different methodologies of data gathering, synthesis and reporting. For example, data from the GBD, differs significantly with data from the World Health Organization (WHO) $[11,12]$ and HIV estimates from national surveillance systems in high-income countries and UNAIDS [13]. In low-income countries (LICs) data from demographic and population surveys differ even within the same region for similar periods of time [14, 15]. Even when there are strategies in place like the Integrated Disease Surveillance and Response (IDSR) strategy for reporting communicable diseases in the WHO African region, they are poorly implemented $[16,17]$. Discrepancies and gaps have led to a call for better data in recent years,

\footnotetext{
* Correspondence: r.wamai@northeastern.edu

${ }^{1}$ Integrated Initiative for Global Health, Department of Cultures, Societies and Global Studies, Northeastern University, Boston, MA, USA

Full list of author information is available at the end of the article
}

e.g., by former WHO Secretary General [18], and subsequent development of Guidelines for Accurate and Transparent Health Estimates Reporting (GATHER) to define and promote best reporting practices for population studies in global and local contexts [19].

Without good data evidence-based public health decisions and interventions cannot be made $[18,20]$. Current global burden of disease assessment shows multiple epidemiological transitions with rising non-communicable diseases (NCDs) and decreasing infectious diseases in prevalence, morbidity and mortality [6, 7]. In 2016, 54.7 million people died of which 72.3\% were from NCDs and $8.4 \%$ from communicable, maternal, neonatal, and nutritional conditions (CMNN) [7]. Comprising $61.4 \%$ of 2.4 billion disability-adjusted life-years (DALYs) in 2016 [21], mortality from NCDs has risen $16.1 \%$ during 2006-2016 [7] and could reach 52 million by 2030 [22, 23]. On the other hand, mortality from all CMNN conditions including HIV/AIDS, tuberculosis, malaria and diarrheal diseases have declined over the same period by $24 \%$ overall [7]. Some LICs like Ethiopia have seen more dramatic decreases of up to 65\% during 1990-2015 [24]. Although CMNN conditions remain a challenge, the decreases have resulted from key breakthroughs in prevention, treatment and control [25].

WHO data shows that $86 \%$ of deaths due to NCDs are in LMICs and most are premature [22]. Among these, cardiovascular diseases (CVDs), diabetes and cancer are the major killers [26]. With 8.2 million deaths and 14.1 million new cases in 2012, cancers are the single leading cause of world-wide deaths with $70 \%$ of the deaths occurring in LMICs [27, 28]. As the primary cause of CVD, hypertension is the leading risk factor for morbidity affecting $24 \%$ of adult men and $20 \%$ of adult women or 1.13 billion adults globally in 2015 [29]. Leading risk 
factors shared among the major NCDs - tobacco use, harmful consumption of alcohol, unhealthy diet, and physical inactivity - are all highly modifiable to prevent nearly half of premature NCD deaths [30-33].

Among LMIC regions, sub-Saharan Africa (SSA) faces the greatest challenge from NCDs that could pose the next 'poverty trap' [34]. While carrying the largest burden of major communicable diseases such as malaria, HIV/AIDS, tuberculosis, and neglected tropical diseases (NTDs) [35-38], the subcontinent is also undergoing critical epidemiological, demographic and socioeconomic transformations including nutrition transitions that are resulting in a rise in NCDs such as cancer, hypertension, obesity and diabetes as earlier predicted [29, 39-44].An ageing and increasing population with simultaneously increasing number of people living with diseases like tuberculosis and HIV poses other challenges for NCD comorbidities [41, 44-49]. For example, a systematic review and meta-analytical study observed accelerated risk of pre-diabetes and diabetes among HIV-positive users of antiretroviral treatment (ART) due to ageing, dyslipidemia, metabolic syndrome, obesity and some ART medications that cause mitochondrial toxicity in long term use [50]. These effects have implications for the WHO recommendation to start ART treatment with initial HIV positivity test [51]. Owing to these patterns of disease, the case to invest more in health in Africa has been made by key global health agencies and key players on the continent including the $\mathrm{WHO}$, the World Bank and the African Union [52].

Taking action on NCDs would save millions of lives and save LMICs an estimated \$7 trillion in economic loses during 2011-2025 [22]. The growing prominence of NCDs led to the 2011 political declaration by the United Nations [53, 54]. Following this the WHO developed a Global Monitoring Framework for NCDs with nine voluntary targets to reduce mortality due to NCDs by $25 \%$ by 2025 [55], a target set to one third by 2030 in the SDG framework [56]. Towards this, surveillance data for NCDs are critically needed to inform interventions for the Global Action Plan for the Prevention and Control of NCDs 2013-2020 [32]. Recent reviews of approaches to data gathering for NCDs in LMICs find limited capacities and systems $[3,8,57-59]$. The approaches range from population and demographic surveys, vital registration systems, and socio-economic, behavioural and utilization surveys. Among the major approaches is the STEPwise approach to surveillance (STEPS) developed by the WHO in 2002 [60].

STEPS is a standardized NCD surveillance protocol involving three different levels of steps to gather self-reported data on demographics and behavioural risk factors physical and biochemical measures from nationally representative populations [60]. Since initiation the
STEPS protocol has undergone multiple revisions given increasing body of knowledge and to serve the NCDs Global Monitoring Framework [61]. With over 120 countries implementing STEPS, it is the most widely used approach to collect data on NCDs and assess population risk-factor profiles to inform, monitor and evaluate policies and interventions $[60,61]$. In the WHO African region 41 countries have implemented the STEPS. Here we summarize results of the Kenya STEPS appearing in this special journal supplement as captured in ten separate articles. We first overview the STEPS method followed by a summary of key findings in each article and then discuss these findings in context of their implications for NCDs surveillance and policy.

\section{Surveillance of NCDs through the STEPS in Kenya}

Prior to the STEPS, national data on NCDs and related risk factors could have been estimated from the Kenya Demographic and Health Survey (KDHS), the 2014 Kenya Global Adult Tobacco Survey (GATS), the 2003 Global School Health Survey on physical inactivity and the GBD studies, and more recently the NCD Risk Factor Collaboration [29]. Covering numerous countries, the DHS Program started collecting data on NCDs by including a blood pressure module in 1998 [57]. In Kenya, the first DHS was conducted in 1989 but the NCD module was only added in the latest (2014) survey. The KDHS covers cancer and hypertension as well as three NCD risk factors (tobacco use, alcohol consumption, and physical inactivity), all of which are self-reported [62]. The GBD estimated that the contribution of NCDs to health loss (DALYs) amounted to 19.4\% in 2000 rising to about $30 \%$ in 2013 [63]. Although the DHS uses a nationally representative sample and the GDB aggregates multiple data sources [57], these reports do not match the depth of measures, methodology and risk-factor analysis capabilities of the STEPS. Aside from the national DHS, NCD data for Kenya are also captured in rural-regional demographic surveys in western Kenya [64] and in the coastal region [65], and in the limited Nairobi cancer registry [66]. In addition, the first Global school-based student health survey (GSHS) was conducted in 2003 [67] and the first Global Tobacco Survey (GTS) in 2014 [68].

These and other disease-specific studies have provided knowledge of NCDs in Kenya as well as risk factors but the prevalence of diseases, their distribution and risk-factors at the national level have not been comprehensively examined. The DHSs have provided evidence that NCDs are prevalent not just in urban but also in rural areas and are rising $[64,65]$ while estimates based on the cancer registry indicate cancer contributes to $7 \%$ of national mortality $[66,69]$. A unique study using the health production function estimated the effect of risk 
factors for NCDs based on national household expenditure and health utilization data [70]. Key risk factors to NCDs were socio-economic (income, education levels), health systems (e.g., distance to health facilities, cost of care), adverse social interactions in area of residence (e.g., availability and consumption of alcohol and smoking and influencing behavioural factors), and biological factors (e.g., age and gender) [70]. The STEPS has allowed a deeper and more comprehensive understanding of the national NCDs risk-factor profile.

\section{Overview of methods for the Kenya STEPS}

The STEPs Kenya 2015 survey was a national cross-sectional household survey conducted between April and June 2015. It was designed to provide estimates for indicators on risk factors for NCDs for persons aged 18-69 years with a sample size of 6,000 individuals to allow national estimates by sex (male and female) and residence (urban and rural areas). Using a three-stage sampling, 200 clusters (100 urban and 100 rural) were selected in stage one, followed by a uniform selection of 30 households in each cluster in stage two, and in stage three one adult aged 18-69 years was randomly selected from each household, with a household defined as people who eat and live together, and approached for the survey. The survey used the fifth $\mathrm{Na}$ tional Sample Surveys and Evaluation Programme (NASSEP V) master sample frame that is developed and maintained by Kenya National Bureau of Statistics. The stratified probability proportional to size sampling methodology was developed using 96,251 Enumeration Areas (EAs) generated from the 2009 Kenya Population and Housing Census to form 5,360 clusters split into four equal sub-samples [62]. National sampling frames are necessary for disease surveillance at the household level and evolve over time to reflect population and administrative changes [71]. The Kenya STEPS thus uses the most recent frame (NASSEP V) which was also used in the latest DHS.

The survey used the modular expanded STEPS collecting demographic and behavioural information (step 1), physical measurements (step 2) and biochemical measures (step 3) [60]. After providing informed consent, the participants were interviewed on the four main behavioural risk factors of NCDs (tobacco use, harmful use of alcohol, unhealthy diets, and physical inactivity), and measurements for key biological risk factors for NCDs (overweight and obesity derived from height and weight and central obesity derived from waist and hip circumference, blood pressure and fasting blood glucose, triglyceride, and cholesterol levels) were also taken. The survey was administered using a Personal Digital Assistant (PDA) loaded with the WHO eSTEPS software. Data collection took place during a two-month period (April-
June) in 2015. Complete details of the sample design, methodology and questionnaire are provided in the formal report published by the Ministry of Health [72]. Each article also summarizes specific methodological method for the relevant question covered.

Research ethics approval for the Kenya STEPS was obtained from Kenya Medical Research Institute (SSC No. 2607). The survey was funded by the World Bank, but the Bank had no role in the decision to publish this special issue nor in interpretation of the results.

\section{Overview of the results of the Kenya STEPS}

The ten individual articles covering the Kenya STEPS data reports the following main findings, without any specific order.

Mohamed and colleagues' paper on hypertension focuses on the prevalence, awareness, treatment and control including determinants. The study reveals that the age-standardized prevalence for hypertension in Kenya was $24.5 \%$ which is similar to the global average [29] but lower than rest of sub-Saharan Africa at 30\% [73]. Among those with hypertension $15.6 \%$ were aware of elevated blood pressure, of whom $26.9 \%$ were on treatment and $51.7 \%$ of those on treatment had achieved blood pressure control. Key factors associated with hypertension were older age, higher body mass index (BMI) and harmful use of alcohol, all of which are characteristic factors in other populations.

Another article by Mohamed and other colleagues analyses data on prevalence and factors associated with pre-diabetes and diabetes mellitus, finding the age-standardized prevalence at $3.1 \%$ and $2.4 \%$, respectively. Nearly half $(43.7 \%)$ were aware of having pre-diabetes or diabetes, a figure that is worse than the global estimate of undiagnosed diabetes of $50 \%$ but better than the Africa estimate of 69\% [74]. About 20\% were on treatment and only $7 \%$ of these had achieved glycaemic control. Low level of education was associated with lower odds of pre-diabetes while raised blood pressure, overweight/obesity among women, and older age (60-69 years) were associated with diabetes.

The article on cervical cancer looks at predictors of cervical cancer screening among women. Among 1,180 women interviewed only $16.4 \%$ had screened for cervical cancer despite high awareness $(67.9 \%$ of unscreened women) of cervical cancer screening. Predictors of screening were higher education levels, being in the highest income quintile and living in urban areas.

Wekesah et al. analyze factors associated with the presence of multiple NCD risk factors at the individual and household levels. Key findings show that over two thirds $(75.8 \%)$ of individuals in this study had four to six risk factors for NCDs and $10 \%$ had seven or more risks. Insufficient fruit and intake was almost universal 
(99.8\%). The overwhelming majority $(89.5 \%$ and $80.3 \%$, respectively) consumed high dietary salt and had insufficient physical activity. The number of NCD risk factors increased with age among both men and women and household wealth index status. Associations of risks with other socio-demographic factors such as income-level, marital status, ethnicity and region differed between sexes. For example, married women had higher odds of more NCD risk factors.

Analysis of risk factors for NCDs and injury adds another perspective from the Kenya STEPS data. Using a $\mathrm{K}$-median cluster analysis approach the article develops a risk profile of the population identifying five clusters for NCDs (hypertensives, harmful users, the hopefuls, the obese, and the fat lovers) and four clusters for injury (helmet users, jaywalkers, the defiant and the compliant). The strongest predictors of clustering were age, gender, education and wealth index. The article's key message is that different portions of the population are exposed to differing risk factors creating the diverse risk profiles. Identifying these risk profiles is critical and confirms that policy formulation and interventions for injuries in particular and NCDs in general need to be differently targeted to mitigate exposure to risk factors, thus prioritizing a "best buys" approach.

The prevalence and the determinants of heavy episodic drinking (HED) were assessed by Kendagor and colleagues. Overall adult HED prevalence was determined to be $12.6 \%$ with men comprising $88.5 \%$ of this group. The $18-29$ years old age group had the highest proportion (35.5\%) of HED. HED was also high (60\%) among the married/cohabiting but even higher among those who were separated. Home-brewed beers or wines were the most commonly reported by almost two thirds of the respondents. Consumption of tobacco was associated with higher odds of HED but the years of schooling, wealth quintile and residence did not have any effect on HED prevalence.

Levels and determinants of tobacco use is the focus of the article by Ngaruiya et al. Tobacco use was reported by $13.5 \%$ of the respondent sample of which $83.8 \%$ of users were men. Among the users $78.8 \%$ did so daily. The average age of starting tobacco use was 21 years and $75 \%$ of users were less than 50 years old and mostly in the 18-29 year-old age group. On the other hand, the 50-59 year age group were three times more likely to use tobacco daily than the younger age groups. Being male, adolescent/youth, and having lower level of education were the main determinants of tobacco use. Majority $(71.7 \%)$ of users had no schooling beyond primary school. Tobacco smoking was more common in urban areas compared to rural areas where smokeless tobacco use was more predominant. Alcohol use had a moderate association on daily tobacco use. An insignificant number reported using e-cigarettes.
Assessing the prevalence and predictors of physical inactivity Gichu et al.'s study finds very low levels of physical inactivity with only $7.7 \%$ of respondents being classified as physically inactive. Being female and of middle age (30-49 years), and having higher education and income levels (middle wealth quintile) were the most important predictors of physical inactivity with area of residence (urban/rural) having little prediction effect.

Mwenda and co-authors analyse patterns of dietary risk factors and association with NCDs. Results show that high (unhealthy) intake of dietary salt and sugar was $18.3 \%$ and $13.7 \%$, respectively. The majority of respondents were aware of health risk from dietary salt $(88 \%)$ and sugar (91\%) although just over half were implementing steps to reduce intake of salt and sugar $(56 \%$ and $54 \%$ of respondents, respectively). Daily intake of a minimum of five servings of both fruits and vegetables was reported by only $6.0 \%$ the respondents. Male gender, being under 46 years old and being a student were strongly associated with unhealthy diet.

Gathecha and colleagues examine prevalence and predictors of injuries. Prevalence of injuries over past 12 months was $15.2 \%$ and $60.3 \%$ were males. The main causes of injuries were falls (47.6\%), cuts (34.0\%) and road traffic crashes (4\%). Injuries due to violent incident was only reported by $3.7 \%$ of respondents. Injuries were significantly more prevalent among rural residents and $40.7 \%$ occurred at home, $16.9 \%$ in the farm and $16.7 \%$ in other work places. Consistent seatbelt use among drivers and passengers was reported by only $12.5 \%, 62 \%$ of motorcycle users never use helmets and drunk driving was reported by $8.1 \%$ of the drivers. Younger males age 18-29 years and smokers were significantly more likely to be injured in a road traffic accident. Binge drinking was a factor in violent incidents as was age 30-39 years. Being in the top two income quintiles was protective against unintentional injuries.

\section{Discussion}

These studies from the Kenya STEPS provide the most comprehensive understanding of NCDs and associated risk factors in the country. To a large degree the results reflect the current stage of demographic and economic transitions. Overall, according to data from the KDHS deaths due to NCDs increased from $35 \%$ of total deaths in 2003 to $45 \%$ in 2010 [64]. In 2018, Kenya's population is estimated at 50.9 million with $72.9 \%$ living in rural areas [48]. After dipping due to the HIV/AIDS crisis in the 1990s, life expectancy has been increasing since 2000 as transitions continue to occur in health and the economy with a growing urbanization and an expanding middle class [41].

Correspondingly, levels of physical inactivity, overweight/obesity nutrition transitions reflect population 
distribution and economic activity. For example, physical inactivity in the STEPS was only $7.7 \%$ compared with that in other higher income-level countries like South Africa (44.7\%) and Swaziland (49.1\%) and the global prevalence of $31 \%$ [75]. Without strong culturally mitigating effects, disease transition models predict these developments to continue to create a society where NCDs dominate commensurate with the dominant risk factor environment [39, 41, 76-79]. For that reason, Kenya needs to vigorously take measures to meet the goals laid out in the Global Action Plan for the Prevention and Control of NCDs 2013-2020 [32], the country's Vision 2030 for a healthy and prosperous nation [80], and the SDG \#3 target 4 of reducing premature mortality due to NCDs by one third by 2030 [81].

The health effects of NCDs and related risk-factors are well established [33, 82-86]. As the Kenya STEPS data show, socio-economic and demographic factors namely, income level, age, gender, urban residence and education are associated with NCDs [70, 72]. Taking action on NCDs would save millions of lives and economic productivity $[34,87,88]$. The WHO estimated that just $\$ 11.2$ billion in annual investments could save $\$ 7$ trillion in lost productivity in LMICs during 2011-2025 [22]. As such, interventions for NCDs are highly cost-effective. For example, nutrition education in New York City public schools was cost-effective in reducing childhood obesity [89]. Effective policy changes are also cost-effective and will decrease NCD costs and prevalence making it the best way to improve overall health for all [90]. Addressing factors contributing to excessive weight gain; smoking and treating hypertension would be cost-effective in tackling NCDs in Kenya [41].

Health benefits resulting from reducing risks for NCDs are huge. Increased longevity resulting from positive change in lifestyle is evident even in older adults aged over 50 years with or without CVDs [83]. Large nationally representative data in the US has recently shown that, compared to the status quo, maintaining a healthy BMI, eating a healthy diet, a moderate use of alcohol, and moderate to vigorous exercise could add over a decade of life for men and women over 50 years of age [85]. Interventions to target one risk factor can often have cascading effects. For example, because physical inactivity is shown to contribute to numerous NCDs including cancer and approximately 30\% of ischaemic heart disease [84] programs to increase physical activity could have huge effects.

Kenya has a national strategy for prevention and control of NCDs for 2015-2020 [91]. A new cancer control strategy for 2017-2022 was recently launched [92]. In addition, the country also has strong policies on smoking and alcohol, namely the Framework Convention for Tobacco Control (FCTC) which the country ratified in
2004, the Kenya Tobacco Control Act of 2007 and the 2010 Alcoholics Drinks Control Act. Despite these policies, laws and strategies, capacity to document, implement, monitor, and evaluate NCD programming in the country as in other LMICs is woefully inadequate [57, 58]. In the 2014 WHO NCDs Country Profiles, Kenya reported negative to having any of the nine national systems to respond to NCDs [93]. The latest (2013) Kenya Service Availability and Readiness Assessment Mapping (SARAM) showed that overall only $5 \%$ of facilities offered all NCD services defined in the Kenya Essential Package of Health (KEPH) and only $25 \%$ of health facilities had different tracer commodities for NCDs with huge regional variations [94]. Strengthening core data for NCDs in vital registration and integrating risk-factor surveillance into policy and programming is essential [59]. Because of complex challenges in standardization experts recommend utilization of mixed data systems, a practice currently in place everywhere although some countries have more robust structures than others $[3,57,59]$.

This special journal issue of the Kenya STEPs survey brought numerous co-author teams together drawn from the Kenya Ministry of Health, the African Population and Health Research Centre (APHRC), other entities and academia both locally and abroad. Altogether, 35 comprising scholars and practitioners in many disciplinary fields contributed to the special issue. The 10 research articles were peer-reviewed by a team of 22 reviewers and 3 editors from different disciplines and institutions around the world. The publication demonstrates the value for international collaborations in research on NCDs. Such collaborations provide opportunities but also challenges [95]. In our case, inter-institutional and interdisciplinary north-south and south-south collaborations were key strengths. Such collaborations provide benefits for science, academic and implementing institutions, and for the individual investigators. In an era where team research is increasingly promoted [96] true collaborations could help improve equity in international health research and increase output by African scholars and practitioners [97, 98]. To our knowledge this is the first time any country has organized to publish comprehensive STEPS data in a special issue in the peer-reviewed literature.

\section{Conclusions}

The 2015 Kenyan STEPS survey provides the first snapshot of major NCDs risk factors burden in the country, serving as baseline against which future progresses will be monitored. Such monitoring should include a repetition of the survey at regular time-intervals. The scope of NCDs and risk factors is too broad to be comprehensively covered in a single survey, including in high-income countries. However, by strategically building into successive surveys, specific modules for key NCDs/risk factors, 
countries over time are able to generate surveillance data for major established and emerging NCDs in their population. Kenya could use a similar approach in future STEPS or similar surveys, to expand the scope of traditional NCD risk factors to lipid disorders including expanding the assessment of diabetes beyond a fasting glucose level that is likely to underestimate the prevalence, to collect data on neglected NCDs like epilepsy and mental health, and on emerging and novel risk factors. This should ideally go in parallel with efforts to develop and maintain complementary data sources, which in the long term, will equip the country with a comprehensive surveillance system for NCDs. With such a pragmatic policy prescription for NCD surveillance, the country also need to step up provision of services for prevention and treatment of NCDs in and outside the health system in line with national and global goals. Ultimately, for Kenya and countries across Africa the path to longer and healthier lives to 2030 [99], and beyond, requires understanding disease profiles matched by the right interventions.

\begin{abstract}
Abbreviations
APHRC: African Population and Health Research Centre; ART: antiretroviral treatment; BMI: Body mass index; CDIA: Chronic Disease Initiative for Africa; CHANCES: Consortium on Health and Ageing Network of Cohorts in Europe and the United States; CMNN: communicable, maternal, neonatal, and nutritional conditions; CVD: Cardiovascular diseases; DALYs: disabilityadjusted life-years; DHS: Demographic and Health Survey; EAs: Enumeration Areas; FCTC: Framework Convention for Tobacco Control; GATHER: Guidelines for Accurate and Transparent Health Estimates Reporting; GATS: Global Adult Tobacco Survey; GBD: Global Burden of Disease; GSHS: Global school-based student health survey; GTS: Global Tobacco Survey; HALE: healthy life expectancy; HDL: High-density lipoproteins; HDSS: Health and Demographic Surveillance System; HED: heavy episodic drinking; IDSR: Integrated Disease Surveillance and Response; KDHS: Kenya Demographic and Health Survey; KEPH: Kenya Essential Package of Health; KNBS: Kenya National Bureau of Statistics; LICS: low-income countries; LMICS: Low- and middle-income countries; NASSEP V: National Sample Surveys and Evaluation Programme; NCDs: Noncommunicable diseases; NTDs: neglected tropical diseases; PCA: principal component analysis; PDA: Personal digital assistant; SARAM: Kenya Service Availability and Readiness Assessment Mapping; SDGs: Sustainable Development Goals; SSA: Sub-Sharan Africa; STEPS: WHO STEPwise approach to Surveillance (of NCD risk factors); WHO: World Health Organization
\end{abstract}

\section{Acknowledgements}

The editors would like to acknowledge all the authors and reviewers of the articles in this special issue of the Kenya STEPS. We acknowledge Kenya's Ministry of Health Unit for NCDs for conducting the STEPS and initiating this special issue. We also acknowledge the APHRC for their role in coordinating this special issue. Acknowledgments are also due to Gandham N.V. Ramana (Lead Health Specialist \& Program Leader, Kenya, Rwanda, Uganda and Eritrea Country Department, Africa Region, The World Bank Group) and Miriam Schneidman (Lead Health Specialist, Eastern and Southern Africa, Health, Nutrition and Population Global Practice, The World Bank Group) for the financial support for conducting the Kenya STEPS. The editors have received no financial or other rewards for their role.

\section{Funding}

Publication of this supplement has been funded by International Development Research Centre (IDRC) grant number 107209-001, through the African Population and Health Research Center (APHRC). The articles have undergone the journal's standard peer review process for supplements. $\mathrm{NL}$ declares to have received funding to attend international conferences from Sanofi and Novo nordisk and whose Unit has received contributions to the salary of a diabetes educator from Roche Diagnostics and Lilly Laboratories. The other Supplement Editors declare that they have no competing interests.

\section{About this supplement}

This article has been published as part of BMC Public Health Volume 18 Supplement 3, 2018: Special issue from national survey on NCD risk factors in Kenya. The full contents of the supplement are available online at https:// bmcpublichealth.biomedcentral.com/articles/supplements/volume-18supplement-3.

\section{Authors' contributions}

RGW conceived the paper and wrote the content outline. APK and NL provided critical comments and guidance on the content outline. RGW wrote the first draft. APK and NL reviewed the draft and provided input. RGW, APK and NL reviewed and approved the final draft for submission.

Ethics approval and consent to participate

Ethical approval for this overall paper is not applicable as we are not using primary data.

\section{Consent for publication}

Not applicable.

\section{Competing interests}

The authors declare that they have no competing interests.

\section{Publisher's Note}

Springer Nature remains neutral with regard to jurisdictional claims in published maps and institutional affiliations.

\section{Author details}

${ }^{1}$ Integrated Initiative for Global Health, Department of Cultures, Societies and Global Studies, Northeastern University, Boston, MA, USA. ${ }^{2}$ Non Communicable Diseases Research Unit, South African Medical Research Council, Francie van Zijl Drive, Parow Valley, Cape Town, Western Cape, South Africa. ${ }^{3}$ Diabetic Medicine and Endocrinology, University of Cape Town, J47/86 Old Main Building Groote Schuur Hospital, Observatory, Cape Town 7925, South Africa. ${ }^{4}$ Chronic Disease Initiative for Africa (CDIA), University of Capetown, J47/86 Old Main Building Groote Schuur Hospital, Observatory, Cape Town 7925, South Africa.

Published: 7 November 2018

\section{References}

1. Thacker SB, Stroup DF, Rothenberg RB. Public health surveillance for chronic conditions: a scientific basis for decisions. Stat Med. 1995;14:629-41.

2. Nsubuga P, White ME, Thacker SB, et al. Public Health Surveillance: A Tool for Targeting and Monitoring Interventions. In: Jamison DT, Breman JG, Measham AR, Alleyne G, Claeson M, Evans DB, Jha P, Mills A, Musgrove P, editors. Disease Control Priorities in Developing Countries. 2nd ed. Washington (DC): World Bank; 2006. Chapter 53.

3. Thacker SB, Qualters JR, Lee LM. Centers for Disease Control and Prevention. Public health surveillance in the United States: evolution and challenges. MMWR Suppl. 2012;61(3):3-9.

4. Horlick G, O'Connor J. The Legal Basis for Public Health Surveillance. In: M'ikanatha NM, Iskander JK, editors. Concepts and Methods in Infectious Disease Surveillance. Oxford: Wiley-Blackwell; 2014.

5. Bennett JE, Dolin R, Blaser MJ, editors. Mandell, Douglas, and Bennett's Principles and Practice of Infectious Diseases. 8th ed. Philadelphia PA: Elsevier Saunders; 2015.

6. World Health Organization. World Health Statistics 2017: Monitoring health for the SDGs. Geneva: WHO; 2017. Available at: http://www.who.int/gho/ publications/world_health_statistics/2017/en/. Accessed 20 Apr 2018

7. GBD 2016 Causes of Death Collaborators. Global, regional, and national agesex specific mortality for 264 causes of death, 1980-2016: a systematic analysis for the Global Burden of Disease Study 2016. Lancet. 2017; 390(10100):1151-210.

8. Jha P. Reliable direct measurement of causes of death in low- and middleincome countries. BMC Med. 2014:12:19.

9. Kean S. Cause of death. Science. 2015;347(6229):1410-3. 
10. World Health Organization. World Health Statistics 2018: Monitoring health for the SDGs. Available at: http://www.who.int/gho/publications/world_ health_statistics/2018/en/. Accessed 10 May 2018.

11. Kassebaum NJ, Lopez AD, Murray CJL, Lozano R. A comparison of materna mortality estimates from GBD 2013 and WHO. Lancet. 2014;384:2209-10.

12. Kovacs SD, Mullholland K, Bosch J, et al. Deconstructing the differences: a comparison of GBD 2010 and CHERG's approach to estimating the mortality burden of diarrhea, pneumonia, and their etiologies. BMC Infect Dis. 2015;15:16.

13. Supervie $V$, Costagliola D. Time for a revolution in tracking the HIV epidemic. Lancet HIV. 2016;3(8):e337-9.

14. Deribew A, Ojal J, Karia B, Bauni E, Oteinde M. Under-five mortality rate variation between the Health and Demographic Surveillance System (HDSS) and Demographic and Health Survey (DHS) approaches. BMC Public Health. 2016;16:1118.

15. Pampel F. Tobacco use in sub-Sahara Africa: estimates from the demographic health surveys. Soc Sci Med. 2008;66:1772-83.

16. Phalkey RK, Yamamoto S, Awate P, Marx M. Challenges with the implementation of an Integrated Disease Surveillance and Response (IDSR) system: systematic review of the lessons learned. Health Policy Plan. 2015;30(1):131-43.

17. Mwatondo AJ, Ng'ang'a Z, Maina C, Makayotto L, Mwangi M, Njeru I, Arvelo W. Factors associated with adequate weekly reporting for disease surveillance data among health facilities in Nairobi County, Kenya, 2013. Pan Afr Med J. 2016;23:165.

18. Chan M. From new estimates to better data. Lancet. 2012;380(9859):2054.

19. Stevens GA, Alkema L, Black RE, Boerma JT, Collins GS, Ezzati M, et al. Guidelines for Accurate and Transparent Health Estimates Reporting: the GATHER statement. PLoS Med. 2016;13(6):e1002056.

20. Annan K. Data can help to end malnutrition across Africa. Nature. 2018;555:7.

21. GBD 2016 DALYs and HALE Collaborators. Global, regional, and national disability-adjusted life-years (DALYs) for 333 diseases and injuries and healthy life expectancy (HALE) for 195 countries and territories, 1990-2016: a systematic analysis for the Global Burden of Disease Study 2016. Lancet. 2017;390(10100):1260-344.

22. WHO. Global status report on noncommunicable diseases 2014. Geneva: WHO; 2015. Available at: http://apps.who.int/iris/bitstream/handle/10665/14 8114/9789241564854 eng.pdf;jsessionid=0DDA0B15612F439BA36F0034AFD 740FE? sequence=1. Accessed 20 Apr 2018

23. Mathers $C D$, Loncar D. Projections of global mortality and burden of disease from 2002 to 2030. PLoS Med. 2006;3(11):e442.

24. Misganaw A, Haregu TN, Deribe K, et al. National mortality burden due to communicable, non-communicable, and other diseases in Ethiopia, 19902015: findings from the Global Burden of Disease Study 2015. Popul Health Metr. 2017;15:29.

25. Fauci AS, Morens DM. The Perpetual Challenge of Infectious Diseases. N Engl J Med. 2012;366(5):454-61.

26. Bowry AD, Lewey J, Dugani SB, Choudhry NK. The Burden of Cardiovascular Disease in Low- and Middle-Income Countries: Epidemiology and Management. Can J Cardiol. 2015;31(9):1151-9.

27. Torre LA, Bray F, Siegel RL, Ferlay J, Lortet-Tieulent J, Jemal A. Global cancer statistics 2012. CA Cancer J Clin. 2015;65(2):87-108.

28. Stewart BW, Wild CP. World Cancer Report 2014. Geneva: World Health Organization, International Agency for Research on Cancer, WHO Press; 2015.

29. NCD Risk Factor Collaboration (NCD-RisC). Worldwide trends in blood pressure from 1975 to 2015: a pooled analysis of 1479 population-based measurement studies with 19.1 million participants. Lancet. 2017;389(10064):37-55.

30. WHO. Global Health Risks: Mortality and burden of disease attributable to selected major risks. 2009. Available at: http://apps.who.int/iris/handle/ 10665/44203. Accessed 30 Apr 2018.

31. GBD 2015 Risk Factors Collaborators. Global, regional, and national comparative risk assess- ment of 79 behavioural, environmental and occupational, and metabolic risks or clusters of risks, 1990-2015: a systematic analysis for the Global Burden of Disease Study. Lancet. 2016;388:1659-724.

32. WHO. Global Action Plan for the Prevention and Control of NCDs 2013 2020; 2013. Available at: http://apps.who.int/iris/bitstream/handle/10665/ 94384/9789241506236_eng.pdf?sequence=1. Accessed 10 May 2018.

33. Daar AS, Singer PA, Persad DL, et al. Grand challenges in chronic noncommunicable diseases. Nature. 2007;450(7169):494-6.

34. Stuckler D, Yach D. Long-term impacts of leading chronic diseases in low- and middle-income countries. In: Gatti A, Boggio A, editors. Health and Development: Toward a Matrix Approach. New York: Palgrave MacMillan; 2009.
35. World Health Organization. World Malaria Report, 2017. Available at: http:// www.who.int/malaria/publications/world-malaria-report-2017/report/en/. Accessed 5 May 2018.

36. World Health Organization. Global Tuberculosis Report 2017. Available at: http://apps.who.int/medicinedocs/documents/s23360en/s23360en.pdf. Accessed 5 May 2018.

37. Olesen OF, Parker Ml. Health research in Africa: getting priorities right. Trop Med Int Health. 2012;17(9):1048-52.

38. Kebede S, Duales S, Yokouide A, Alemu W. Trends of major disease outbreaks in the African region, 2003-2007. East Afr J Public Health. 2010;7(1):20-9.

39. National Research Council (US). The Continuing Epidemiological Transition in Sub-Saharan Africa. Washington (DC): National Academies Press (US); 2012. ISBN-13: 978-0-309-26648-2. https://www.ncbi.nlm.nih.gov/books/ NBK105418/. Accessed May 11, 2018

40. Popkin BM, Adair LS, Ng SW. The Global Nutrition Transition: The Pandemic of Obesity in Developing Countries. Nutr Rev. 2012;70(1):3-21.

41. Institute for Health Metrics and Evaluation, Human Development Network The World Bank. The Global Burden of Disease: Generating Evidence, Guiding Policy — Sub-Saharan Africa Regional Edition. Seattle, WA: IHME; 2013. Available at: http://www-wds.worldbank.org/external/default/ WDSContentServer/WDSP/IB/2013/09/03/000456288_20130903110819/ Rendered/PDF/808520PUBOENGLOBox0379820B00PUBLIC0.pdf. Accessed 25 Apr 2018.

42. Sylla BS, Wild CP. A million Africans a year dying from cancer by 2030: what can cancer research and control offer to the continent? Int J Cancer. 2011. 130(2):245-50.

43. Guariguata L, Whiting DR, Hambleton I, Beagley J, Linnenkamp U, Shaw JE. Global estimates of diabetes prevalence for 2013 and projections for 2035. Diabetes Res Clin Pract. 2014;103(2):137-49.

44. Atun R, Davies JI, Gale EAM, et al. Diabetes in sub-Saharan Africa: from clinical care to health policy. Lancet Diabetes Endocrinol. 2017;5(8):622-67.

45. Levitt NS, Steyn K, Dave J, Bradshaw D. Chronic noncommunicable diseases and HIV-AIDS on a collision course: relevance for health care delivery, particularly in low-resource settings-insights from South Africa. Am J Clin nutr. 2011;94(6):1690S-6S.

46. Marais B, Lönnroth K, Lawn SD, et al. Tuberculosis comorbidity with communicable and non-communicable diseases: integrating health services and control efforts. Lancet Infect Dis. 2013;13(5):436-48.

47. Institute of Medicine. Preparing for the future of HIV/AIDS in Africa: a shared responsibility. Washington, DC: National Academies Press; 2011.

48. United Nations. World Population Prospects: The Revision 2017. Available at: https://population.un.org/wpp/. Accessed 30 Apr 2018.

49. Oni T, Berkowitz N, Kubjane M, Goliath LNS, Wilkinson RJ. Trilateral overlap of tuberculosis, diabetes and HIV-1 in a high-burden African setting: implications for TB control. Eur Respir J. 2017;50(1):1700004.

50. Nansseu JR, Bigna JJ, Kaze AD, Noubiap JJ. Incidence and Risk Factors for Prediabetes and Diabetes Mellitus Among HIV-infected Adults on Antiretroviral Therapy: A Systematic Review and Meta-analysis. Epidemiology. 2018;29(3):431-41.

51. WHO. Guideline on when to start antiretroviral therapy and on preexposure prophylaxis for HIV. September 2015. Available at: http://www. who.int/hiv/pub/guidelines/earlyrelease-arv/en/. Accessed 25 Apr 2018.

52. Harmonization for Health in Africa. The Case for Strengthening Systems for Better Health Outcomes. 2011. Available at: http://www.who.int/pmnch/topics/ economics/20110414_investinginhealth_africa/en/. Accessed May 10, 2018.

53. Marrero SL, Bloom DE, Adashi EY. Noncommunicable Diseases: A Global Health Crisis in a New World Order. JAMA. 2012;307(19):2037-8.

54. Alwan AD, Galea G, Stuckler D. Development at risk: addressing noncommunicable diseases at the United Nations high-level meeting. Bull World Health Organ. 2011;89(8):546-546A.

55. WHO. NCD Global Monitoring Framework. Available at: http://www.who.int/ nmh/global_monitoring_framework/en/. Accessed 30 Apr 2018.

56. United Nations. Sustainable Development Goals. 2015. Available at: https:// sustainabledevelopment.un.org/sdgs. Accessed 11 May 2018.

57. Kengne AP, Echouffo-Tcheugui JB, Yaya S, Joshi R. Population Surveillance and Chronic Non-communicable Diseases. In: Graft Aikins A, de Agyemang C, editors. Chronic Non-communicable Diseases in Low- and Middle-income Countries. Wallingford: CAB International; 2016

58. Kroll M, Phalkey RK, Kraas F. Challenges to the surveillance of noncommunicable diseases - a review of selected approaches. BMC Public Health. 2015;15:1243. 
59. Alwan A, MacLean DR, Riley LM, d'Espaignet ET, Mathers CD, Stevens GA, et al. Monitoring and surveillance of chronic non-communicable diseases: progress and capacity in high-burden countries. Lancet. 2010;376:1861-8.

60. WHO. WHO STEPS Surveillance Manual: The WHO STEPwise Approach to Chronic Disease Risk Factor Surveillance. Geneva: World Health Organization; 2008. Available at: http://apps.who.int/iris/handle/10665/ 43376. Accessed 30 Apr 2018

61. Riley L, Guthold R, Cowan M, et al. The World Health Organization STEPwise Approach to Noncommunicable Disease Risk-Factor Surveillance: Methods, Challenges, and Opportunities. Am J Public Health. 2016;106(1):74-8.

62. Kenya National Bureau of Statistics (KNBS), ICF Macro. Kenya Demographic and health survey 2014. Calverton: KNBS and ICF Macro; 2015.

63. Institute for Health Metrics and Evaluation and the International Centre for Humanitarian Affairs. The Global Burden of Disease: Generating Evidence, Guiding Policy in Kenya. Nairobi; 2016. Available at: http://www.healthdata. org/policy-report/global-burden-disease-generating-evidence-guidingpolicy-kenya. Accessed 30 Apr 2018

64. Phillips-Howard PA, Laserson KF, Amek N, Beynon CM, Angell SY, et al. Deaths Ascribed to Non-Communicable Diseases among Rural Kenyan Adults Are Proportionately Increasing: Evidence from a Health and Demographic Surveillance System, 2003-2010. PLoS ONE. 2014:9(11):e114010.

65. Etyang AO, Munge $\mathrm{K}$, Bunyasi EW, et al. Burden of disease in adults admitted to hospital in a rural region of coastal Kenya: an analysis of data from linked clinical and demographic surveillance systems. Lancet Glob Health. 2014;2(4):e216-24.

66. Korir A, Gakunga R, Subramanian S, et al. Economic analysis of the Nairobi Cancer Registry: Implications for expanding and enhancing cancer registration in Kenya. Cancer Epidemiol. 2016 Dec;45(1):S20-9.

67. WHO. Global school-based student health survey; 2003. Available at: http:// www.who.int/ncds/surveillance/gshs/kenya/en/. Accessed 20 May 2018.

68. Ministry of Health; Tobacco Control Unit and Kenya National Bureau of Statistics (KNBS). Kenya Global Tobacco Survey. Nairobi: Ministry of Health; 2014. p. 2016

69. Ministry of Public Health and Sanitation, Ministry of Medical Services. National cancer control strategy 2011-2016. Nairobi: Ministry of Public Health and Sanitation; 2011.

70. Mwai D, Muriithi M. Non-communicable diseases risk factors and their contribution to NCD incidences in Kenya. Eur Sci J. 2015;11(30):268-81.

71. Murthy MN. Master sampling frame and master sample for household sample surveys in developing countries. Rural Demogr. 1981;8(1):13-27.

72. Ministry of Health, Division of Noncommunicable Diseases. Kenya STEPwise survey for noncommunicable diseases risk factors 2015 report. Nairobi: $\mathrm{MOH} ; 2015$.

73. Ataklte F, Erqou S, Kaptoge S, Taye B, Echouffo-Tcheugui JB, Kengne AP. Burden of Undiagnosed Hypertension in Sub-Saharan Africa a systematic review and meta-analysis. Hypertension. 2015;65(2):291-8.

74. International Diabetes Federation. IDF Diabetes Atlas Eight edition 2017. Brussels: IDF; 2017.

75. Guthold R, Ono T, Strong KL, Chatterji S, Morabia A. Worldwide variability in physical inactivity: a 51-country survey. Am J Prev Med. 2008;34(6):486-94

76. Caballero B. The Global Epidemic of Obesity: An Overview. Epidemiol Rev. 2007;29:1-5.

77. Hosseinpoor AR, Bergen N, Kunst A, Harper S, Guthold R, Rekve D, d'Espaignet ET, Naidoo N, Chatterji S. Socioeconomic inequalities in risk factors for non communicable diseases in low-income and middle-income countries: results from the World Health Survey. BMC Public Health. 2012; 12(1):912.

78. Muthuri SK, Francis CE, Wachira L-JM, LeBlanc AG, Sampson M, et al. Evidence of an overweight/obesity transition among school-aged children and youth in sub-Saharan Africa: a systematic review. PLoS ONE. 2014;9(3):e92846.

79. Huang H, Yan Z, Chen Y, Liu F. A social contagious model of the obesity epidemic. Sci Rep. 2016;6(37961). https://doi.org/10.1038/srep37961.

80. Government of the Republic of Kenya. Kenya Vision 2030: A Globally Competitive and Prosperous Kenya. Nairobi: Ministry of Planning and Development; 2007.

81. United Nations. Sustainable Development Goals. Available at: https://www. un.org/sustainabledevelopment/sustainable-development-goals/. Accessed 11 May 2018

82. The GBD. 2015 Obesity Collaborators. Health Effects of Overweight and Obesity in 195 Countries over 25 Years. N Engl J Med. 2017:377:13-27.
83. O'Doherty MG, Cairns K, O'Neill V, et al. Effect of major lifestyle risk factors, independent and jointly, on life expectancy with and without cardiovascular disease: results from the Consortium on Health and Ageing Network of Cohorts in Europe and the United States (CHANCES). Eur J Epidemiol. 2016;31:455-68

84. Kyu H, Bachman VF, Alexander LT, et al. Physical activity and risk of breast cancer, colon cancer, diabetes, ischemic heart disease, and ischemic stroke events: systematic review and dose-response meta-analysis for the Global Burden of Disease Study 2013. BMJ. 2016;i3857:354.

85. Li Y, Pan A, Dong D, et al. Impact of Healthy Lifestyle Factors on Life Expectancies in the US Population. Circulation. 2018;137(18) published online April 30, 2018.

86. 2018 Physical Activity Guidelines Advisory Committee. 2018 Physical Activity Guidelines Advisory Committee Scientific Report. Washington, DC: U.S. Department of Health and Human Services; 2018. Available at: https:// health.gov/paguidelines/second-edition/report/pdf/PAG_Advisory_ Committee_Report.pdf. Accessed 10 April 2018

87. Kankeu HT, Saksena P, Xu K, Evans DB. The financial burden from noncommunicable diseases in low- and middle-income countries: a literature review. Health Res Policy Syst. 2013;11:31

88. Bommer C, Heesemann E, Sagalova V, et al. The global economic burden of diabetes in adults aged 20-79 years: a cost-of-illness study. Lancet Diabetes Endocrinol. 2017 Jun;5(6):423-30

89. Graziose MM, Koch PA, Wang YC, Lee Gray H, Contento IR. Costeffectiveness of a nutrition education curriculum intervention in elementary schools. J Nutr Educ Behav. 2017:49(8):684-691. e1.

90. Jamison DT, Breman JG, Measham AR. Cost-Effective Strategies for Noncommunicable Diseases, Risk Factors, and Behaviors. In: Jamison DT, Breman JG, Measham AR, editors. Priorities in Health. Washington (DC): The International Bank for Reconstruction and Development/The World Bank; 2006. p. 97-128.

91. Republic of Kenya. Kenya National Strategy for the Prevention and Control of Non-Communicable Diseases 2015-2020. Nairobi: Ministry of Health Division of Non-communicable Diseases; 2015

92. Ministry of Health. National Cancer Control Strategy 2017-2022. Nairobi: Ministry of Health; 2017.

93. World Health Organization. Noncommunicable Diseases (NCD) Country Profiles, 2014. Geneva: WHO; 2014.

94. Government of Kenya. Kenya Service Availability and Readiness Assessment Mapping (SARAM). Nairobi: Ministry of Health; 2014.

95. Jaacks LM, Ali MK, Bartlett J, et al. Global Noncommunicable Disease Research: Opportunities and Challenges. Ann Intern Med. 2015;163(9):712-4.

96. Tachibana C. Navigating collaborative grant research, Science. 2013; Available at: http://www.sciencemag.org/features/2013/09/navigatingcollaborative-grant-research. Accessed 28 May 2018.

97. Junghanss T. North-South collaboration to improve health. Trop Med Int Health. 2005;10(2):117

98. Munung NS, Mayosi BM, de Vries J. Equity in international health research collaborations in Africa: Perceptions and expectations of African researchers. PLoS One. 2017;12(10):e0186237.

99. Agyepong IA, Sewankambo N, Binagwaho A, et al. The path to longer and healthier lives for all Africans by 2030: the Lancet Commission on the future of health in sub-Saharan Africa. Lancet. 2018;390(10114):2803-59.

Ready to submit your research? Choose BMC and benefit from:

- fast, convenient online submission

- thorough peer review by experienced researchers in your field

- rapid publication on acceptance

- support for research data, including large and complex data types

- gold Open Access which fosters wider collaboration and increased citations

- maximum visibility for your research: over $100 \mathrm{M}$ website views per year

At BMC, research is always in progress.

Learn more biomedcentral.com/submission 